\title{
Tailoring lattice strain in ultra-fine high-entropy alloys for active and stable methanol oxidation
}

\author{
Dongdong Wang ${ }^{1 \dagger}$, Zhiwen Chen ${ }^{2 \dagger}$, Yu-Cheng Huang ${ }^{5 \dagger}$, Wei $\mathrm{Li}^{1 \dagger}$, Juan Wang ${ }^{6}$, Zhuole $\mathrm{Lu}^{2}$, \\ Kaizhi Gu ${ }^{1}$, Tehua Wang ${ }^{1}$, Yujie $\mathrm{Wu}^{1}{ }^{*}$, Chen $\mathrm{Chen}^{1}$, Yiqiong Zhang ${ }^{3^{*}}$, Xiaoqing Huang ${ }^{6}$, Li Tao ${ }^{1^{*}}$, \\ Chung-Li Dong ${ }^{5^{*}}$, Jun Chen ${ }^{4^{*}}$, Chandra Veer Singh ${ }^{2^{*}}$ and Shuangyin Wang ${ }^{1^{*}}$
}

\begin{abstract}
High-entropy alloys (HEAs) have been widely studied due to their unconventional compositions and unique physicochemical properties for various applications. Herein, for the first time, we propose a surface strain strategy to tune the electrocatalytic activity of HEAs for methanol oxidation reaction (MOR). High-resolution aberration-corrected scanning transmission electron microscopy (STEM) and elemental mapping demonstrate both uniform atomic dispersion and the formation of a face-centered cubic (FCC) crystalline structure in PtFeCoNiCu HEAs. The HEAs obtained by heat treatment at $700^{\circ} \mathrm{C}$ (HEA-700) exhibit $0.94 \%$ compressive strain compared with that obtained at $400^{\circ} \mathrm{C}$ (HEA-400). As expected, the specific activity and mass activity of HEA-700 is higher than that of HEA-400 and most of the state-of-the-art catalysts. The enhanced MOR activity can be attributed to a shorter Pt-Pt bond distance in HEA-700 resulting from compressive strain. The nonprecious metal atoms in the core could generate compressive strain and down shift d-band centers via electron transfer to surface Pt layer. This work presents a new perspective for the design of high-performance HEAs electrocatalysts.
\end{abstract}

Keywords: high-entropy alloys, lattice strain, methanol oxidation, platinum-based catalysts, electrocatalysis

\section{INTRODUCTION}

The direct methanol fuel cell (DMFC) is one of the most promising energy conversion devices. The performance of DMFC is hindered by the inefficient methanol oxidation reaction (MOR) which occurs at the anode. Currently, the most efficient electrocatalysts for the MOR are Pt-based $[1,2]$. However, due to their high cost, low utilization rate, and poor stability which is caused by the dissolution and agglomeration of $\mathrm{Pt}$, and is especially sensitive to toxicity of the intermediate $\mathrm{CO}$, the practical application of Ptbased catalyst is limited $[3,4]$. Therefore, it is significantly important to rationally regulate the components and electronic structure of the anode to improve the $\mathrm{CO}$ poisoning resistance and catalytic activity of Pt-based materials.

Multi-component alloys formed from $\mathrm{Pt}$ and some transition metals (such as $\mathrm{Fe}, \mathrm{Ni}, \mathrm{Cu}$ and $\mathrm{Co}$ ) can significantly reduce the cost, while potentially increasing the overall catalyst activity resulting from synergistic effects (electronic and/or strain effects). The introduction of transition metals not only increases the stability of the material system, but also improves the tolerance of $\mathrm{CO}$ on the Pt surface [5]. As a paradigm of the multi-component alloys, high-entropy alloys (HEAs) are emerging materials which have attracted tremendous attention in many fields due to their tunable composition and tailoring of functional properties [6-11]. Unlike conventional alloys which do not exceed three elements, HEAs are usually defined as alloys containing five or more main elements

\footnotetext{
${ }^{1}$ State Key Laboratory of Chemo/Bio-Sensing and Chemometrics, College of Chemistry and Chemical Engineering, Hunan University, Changsha 410082

${ }^{2}$ Department of Materials Science and Engineering, University of Toronto, Toronto ON M5S 3E4

${ }^{3}$ College of Materials Science and Engineering, Changsha University of Science \&Technology, Changsha 410114

${ }^{4}$ ARC Centre of Excellence for Electromaterials Science, Intelligent Polymer Research Institute (IPRI), Australian Institute of Innovative Materials (AIIM), University of Wollongong, Wollongong NSW 2522

${ }^{5}$ Research Center for X-Ray Science \& Department of Physics, Tamkang University, New Taipei City 25137

${ }^{6}$ College of Chemistry, Chemical Engineering and Materials Science, Soochow University, Suzhou 215123

$\uparrow$ These authors contributed equally to this work.

* Corresponding authors (emails: yqzhang@csust.edu.cn (Zhang Y); taoli@hnu.edu.cn (Tao L); cldong@mail.tku.edu.tw (Dong CL); junc@uow.edu.au (Chen J); chandraveer.singh@utoronto.ca (Singh CV); shuangyinwang@hnu.edu.cn (Wang S))
} 
in an equal or near-equal atomic percentage (at\%) with no distinction between subject and object elements, and these constituent atoms are uniformly distributed in a single-phase solid solution $[12,13]$. Owing to the strong synergistic effects among constituent elements, HEAs often exhibit unique characteristics such as the highentropy effect, the sluggish diffusion effect, severe latticedistortion, and the cocktail effect [14-17].

In recent years, researchers have been seeking various methods and strategies to improve the electrocatalytic activity and stability of HEAs. For instance, Lacey et al. [18] prepared multi-component alloy nanoparticles with controlled compositions for oxygen electrocatalysis by a harsh synthetic method. Similarly, Qiu et al. [19] developed a simple and scalable strategy to prepare ultrafine nano-porous HEAs for the oxygen reduction reaction (ORR). Qiu et al. [20] also prepared nano-porous HEAs using a controllable and traditional method for the oxygen evolution reaction (OER). Given that adjusting the surface strain has become one of the most effective strategies to improve the catalytic performance of electrocatalysts [21,22], Strasser et al. [23] demonstrated that appropriate compressive strain can enhance the catalytic activity of Pt-based alloys by changing the electronic band structure of platinum. Therefore, it is very important to develop Pt-based HEAs and adjust the surface strain of the electrocatalyst to enhance the catalytic activity $[24,25]$.

Herein, we successfully synthesized a class of HEAs with face centered cubic (FCC) structure through an impregnation followed by thermal reduction at different temperatures $\left(400\right.$ and $\left.700^{\circ} \mathrm{C}\right)$ under $\mathrm{H}_{2} / \mathrm{Ar}$ atmosphere. Importantly, HEA-700 (lattice fringes with spacings of $2.12 \AA$ ) exhibits a typical compressive strain compared with HEA-400 (lattice fringes with spacings of $2.14 \AA$ ). As far as we know, this is the first time that a surface strain strategy is used to enhance the catalytic activity of HEAs. Interestingly, both HEA-400 and HEA-700 achieve excellent MOR activity in acidic solution with the specific activities (mass activities) of $2.35 \mathrm{~mA} \mathrm{~cm}^{-2}\left(1.30 \mathrm{~A} \mathrm{mg}^{-1}\right)$ and $3.29 \mathrm{~mA} \mathrm{~cm}^{-2}\left(1.40 \mathrm{~A} \mathrm{mg}^{-1}\right)$, respectively, which are 1.57 (2.32) and 2.20 (2.50) times higher than that of $\mathrm{Pt} / \mathrm{C}$, respectively. In particular, HEA-700 displays higher catalytic activity compared with HEA-400, suggesting that the surface compressive strain in HEAs is able to boost MOR performance. Extended X-ray absorption fine structure (EXAFS) tests reveal that the enhanced MOR activity could be attributed to a shorter Pt-Pt bond distance in HEA-700 resulting from the compressive strain, which can significantly improve the electrocatalytic ac- tivity by downshifting of d-band centers. In addition, density functional theory (DFT) calculations indicate that the compression strain shifts the d-band centers away from the Fermi energy, resulting in a weaker adsorption of CO on the HEA-700 surface and consequently, a higher MOR performance.

\section{EXPERIMENTAL SECTION}

\section{Synthesis of HEA-400}

Vulcan XC-72 carbon supported $\mathrm{PtFeCoNiCu} / \mathrm{C}$ with $20 \mathrm{wt} \%$ metal content was prepared by an impregnation reduction process. The typical synthesis of $\mathrm{PtFeCoNiCu/}$ $\mathrm{C}$ involved the use of five metal precursors, $\mathrm{H}_{2} \mathrm{PtCl}_{6}$. $6 \mathrm{H}_{2} \mathrm{O}, \mathrm{CoCl}_{2} \cdot 6 \mathrm{H}_{2} \mathrm{O}, \mathrm{NiCl}_{2} \cdot 6 \mathrm{H}_{2} \mathrm{O}, \mathrm{CuCl}_{2} \cdot 2 \mathrm{H}_{2} \mathrm{O}$ and $\mathrm{FeCl}_{3}$. These precursors with controlled molar ratios (metal molar ratio is 1:1:1:1:1) were dissolved in deionized water, and then a given amount of Vulcan XC-72 carbon support treated by $\mathrm{O}_{2}$ plasma for $30 \mathrm{~min}$ was added into the above mixture. The suspension was stirred overnight, and then heated under magnetic stirring until the water evaporates formed a smooth thick slurry. The resulting powder was ground in an agate mortar after drying in an oven at $60^{\circ} \mathrm{C}$ for $12 \mathrm{~h}$, yielding the HEA precursor. The HEA-400 was finally obtained by calcinating the precursor at $400^{\circ} \mathrm{C}$ under $10 \% \mathrm{H}_{2} / \mathrm{Ar}$ for $2 \mathrm{~h}$. $\mathrm{Pt} / \mathrm{C}(20 \mathrm{wt} \%)$, binary $\mathrm{PtFe} / \mathrm{C}$, ternary $\mathrm{PtFeCo} / \mathrm{C}$, quaternary $\mathrm{PtFeCoNi} /$ $\mathrm{C}$ and HEAs with different Pt contents (including 5, 10, and $20 \mathrm{wt} \%$, denoted as $x \%$-HEA-400/700, where $x$ is the Pt content) were also prepared by the above method.

\section{Synthesis of HEA-700}

The as-prepared HEA- 400 sample was annealed at $700^{\circ} \mathrm{C}$ under $10 \% \mathrm{H}_{2} / \mathrm{Ar}$ for $2 \mathrm{~h}$ to get HEA-700.

\section{Characterization}

The morphology and microstructures of all samples were characterized by a transmission electron microscope (TEM, FEI, F20 S-TWIX). High-resolution aberrationcorrected scanning TEM (STEM) bright-field and mapping images for HEAs were collected from a probe-corrected JEOL ARM200F. The crystal phase of the products was examined by X-ray diffraction (XRD, Bruker, D8Advance). The actual metal contents in the HEAs were determined by inductively coupled plasma optical emission spectroscopy (ICP-OES, Spectro Blue Sop). The Xray photoelectron spectroscopic (XPS) measurements were carried out with an ESCALAB 250Xi. X-ray ab- 
sorption spectroscopy was conducted at TLS BL17C. The specific surface area of the samples was calculated using the Brunauer-Emmett-Teller (BET) method.

\section{Electrochemical measurements}

All of the electrochemical measurements were performed with a CHI 760D electrochemical workstation with a three-electrode system at room temperature. The catalyst dropped on a glassy carbon electrode $(5 \mathrm{~mm}$ in diameter, $0.196 \mathrm{~cm}^{2}$ ) was used as the working electrode, graphite rod was used as the counter electrode and saturate calomel electrode (SCE) was used as the reference electrode. All potentials in this study were given versus SCE. The electrochemical activities of HEA-400, HEA-700 and Pt/C electrocatalysts were measured for the electro-oxidation of methanol. Generally, $4 \mathrm{mg}$ of electrocatalyst sample was ultrasonically dispersed in $950 \mu \mathrm{L}$ isopropanol and $50 \mu \mathrm{L}$ Nafion solution (5wt\%, Du Pont) to form a homogeneous ink followed by dropping $10 \mu \mathrm{L}$ of the electrocatalyst ink onto the surface of a glass carbon electrode (GCE) and dried under room temperature. The electrochemical active areas of all electrocatalysts were measured in a $\mathrm{N}_{2}$-saturated $0.1 \mathrm{~mol} \mathrm{~L}^{-1} \mathrm{HClO}_{4}$ solution at a scan rate of $50 \mathrm{mV} \mathrm{s}^{-1}$. The electrocatalytic activity for the MOR was measured in a nitrogen-saturated $0.1 \mathrm{~mol} \mathrm{~L}^{-1} \mathrm{HClO}_{4}$ and $1.0 \mathrm{~mol} \mathrm{~L}^{-1} \mathrm{CH}_{3} \mathrm{OH}$ solution at a scan rate of $50 \mathrm{mV} \mathrm{s}^{-1}$. The electrocatalytic activity of the HEA-700 toward CO oxidation was contrasted with HEA-400 and Pt/C catalysts in $0.1 \mathrm{~mol} \mathrm{~L}^{-1} \mathrm{HClO}_{4}$ electrolyte at a scan rate of $10 \mathrm{mV} \mathrm{s}^{-1}$. High purity $\mathrm{CO}$ was bubbled into the electrolyte solution for $20 \mathrm{~min}$ while keeping the electrode potential at $-0.1 \mathrm{~V}$ to achieve maximum coverage of $\mathrm{CO}$ at the Pt centers.

The electrochemically active surface areas (ECSAs) of HEA-400, HEA-700 and Pt/C were calculated by measuring the charge from the $\mathrm{CO}$ adsorption peaks, with the assumption that the smooth $\mathrm{Pt}$ electrode gives the $\mathrm{CO}$ adsorption a charge of $420 \mu \mathrm{C} \mathrm{cm}^{-2}$, which represents the quantity of charge corresponding to the adsorption of a monolayer of CO on Pt site. CO stripping voltammetry was applied to evaluate the ECSA of the catalyst, and the ECSA is calculated by

$\mathrm{ECSA}=\frac{Q_{\mathrm{CO}}}{420 \times M_{\mathrm{Pt}}}$,

where $Q_{\mathrm{CO}}$ is the charge due to the $\mathrm{CO}$ adsorption in the CO stripping voltammograms, 420 represents the charge density $\left(\mu \mathrm{C} \mathrm{cm}^{-2}\right)$ which is required to oxidize a monolayer of $\mathrm{CO}$ on the $\mathrm{Pt}$ site, and $M_{\mathrm{Pt}}$ is the loading of $\mathrm{Pt}$ catalyst on the working electrode.

\section{Calculation of entropy value in HEAs}

According to the Boltzmann's thermodynamic statistics principle and Sterling formula, the configurational entropy $\left(\Delta S_{\text {conf }}\right)$ in system is dominant over the other three contributions including vibrational entropy, magnetic dipole entropy and electronic randomness entropy. Therefore, the quantitative relationship between the entropy and randomness of the system is given by

$$
\begin{aligned}
\Delta S_{\mathrm{conf}} & =-R\left[c_{1} \ln c_{1}+\cdots+c_{n} \ln c_{n}\right] \\
& =-R \sum_{i=1}^{n} c_{i} \ln c_{i},
\end{aligned}
$$

where $R$ is the gas constant, and $c_{i}$ is the mole fraction of the $i^{\text {th }}$ element, and $n$ is the number of the components. When $c_{1}=c_{2}=c_{3}=\ldots=c_{n}$, the entropy of the HEAs system reaches its maximum value.

\section{DFT calculation methods}

All calculations were implemented by spin-polarized DFT in the Vienna $A b$ initio Simulation Package (VASP). The projector augmented wave (PAW) pseudopotential and Perdew-Burke-Ernzerhof (PBE) functional of the generalized gradient approximation (GGA) were utilized to describe the interactions between valence electrons and ionic cores, and the exchange-correlation effects. The kinetic energy cutoff for the wave function calculations was $550 \mathrm{eV}$ with the smearing width of $0.2 \mathrm{eV}$. The supercell of $4 \times 4$ and the vacuum gap of about $15 \AA$ were used for negligible interactions between the systems and their mirror images. The van der Waals interaction was described through zero damping DFT-D3 method of Grimme. The geometry relaxation was stopped if the total energy change and forces between two steps were smaller than $1 \times 10^{-5} \mathrm{eV}$ and $0.05 \mathrm{eV} \AA^{-1}$, respectively. The Bader charge analysis was considered for understanding the charge transfers.

The surface structures of HEAs with four atomic layers were created by the random distribution of metal atoms and the two bottom layers were fixed during geometric relaxation. The top layer only contained Pt atoms because the other metals were dissolved in the initial catalytic process, identified by experimental results. The designed content $\left(\mathrm{Pt}_{26} \mathrm{Fe}_{8} \mathrm{Co}_{10} \mathrm{Ni}_{9} \mathrm{Cu}_{11}\right)$ and lattice constant of HEAs were based on the experimental values. The adsorption energy $\left(E_{\mathrm{ad}}\right)$ of $\mathrm{CO}$ on different catalysts was defined as

$E_{\mathrm{ad}}=E_{\mathrm{CO}^{*}}-\left(E_{\text {catalysts }}+E_{\mathrm{CO}}\right)$,

where $E_{\mathrm{CO} *}, E_{\text {catalysts }}$, and $E_{\mathrm{CO}}$ indicated the total energies of $\mathrm{CO}$ adsorbed on catalysts, isolated catalysts, and $\mathrm{CO}$ 
molecule, respectively.

\section{RESULTS AND DISCUSSION}

In synthesis, $\mathrm{H}_{2} \mathrm{PtCl}_{6} \cdot 6 \mathrm{H}_{2} \mathrm{O}$ and transition metal chlorides $\left(\mathrm{MCl}_{x} \cdot n \mathrm{H}_{2} \mathrm{O}, \mathrm{M}=\mathrm{Fe}, \mathrm{Co}, \mathrm{Ni}\right.$ and $\left.\mathrm{Cu}\right)$ were chosen as the starting materials, Vulcan XC-72 was used as the carbon support. As shown in Scheme S1, we have successfully prepared a class of HEAs at different temperatures under a flowing $\mathrm{H}_{2} / \mathrm{Ar}$ atmosphere. Notably, when the alloy becomes a disordered FCC structure, different atoms will occupy the lattice position randomly, resulting in severe lattice distortion because of the different atomic radii of the constituent atoms (Fig. 1a).

As indicated by the XRD pattern of Fig. 1b, the HEA400 shows a typical platinum-like FCC structure. The three main peaks are consistent with those of a typical FCC structure, corresponding to the (111), (200) and (220) planes. However, the peak positions shift to a higher angle than pure $\mathrm{Pt}$, which indicates that transition metals ( $\mathrm{Fe}, \mathrm{Ni}, \mathrm{Cu}$ and $\mathrm{Co}$ ) were successfully alloyed with $\mathrm{Pt}$ to form a single-phase solid solution with some lattice contraction (Fig. S1). Unexpectedly, after heat-treatment at $700^{\circ} \mathrm{C}$, the HEA-700 maintains the FCC structure well rather than converting to an ordered alloy as usual
$[26,27]$. This may be because the high mixing entropy not only effectively reduces the free energy in the alloy system $\left(\Delta G_{\text {mix }}=\Delta H_{\text {mix }}-T \Delta S_{\text {mix }}\right)$ but also offsets the strain energy, making alloying atoms randomly distributed on the lattice position, thereby reducing the tendency of the alloy atom ordering and segregation, and inhibiting the formation of intermetallic compounds and the occurrence of phase separation $[16,28,29]$. The diffraction peaks of HEA-700 move to higher angles compared with HEA-400 due to the compressive strain $[22,24]$. This also demonstrates the HEA-700 had a better alloy structure. In addition, the calculations results agree well with the respective experimental data (Fig. S2), and the calculated lattice constant of HEA-700 $(a=3.67 \AA)$ is less than that of HEA-400 ( $a=3.71 \AA)$. To some extent, this also confirms the existence of compressive strain. ICP-OES was used for qualitative and quantitative analysis of elements in HEAs. Experimental data show that the five elements have approximately equal molar ratios (Table S1). High-resolution aberration-corrected STEM EDS pattern (STEM-EDS) of the HEAs also confirmed the existence of the above five elements (Fig. 1c and Fig. S3a). In addition, the $\Delta S_{\text {conf }}$ of the HEAs is about $1.61 R$ ( $R$ is the gas constant), satisfying the definition of HEAs [12].
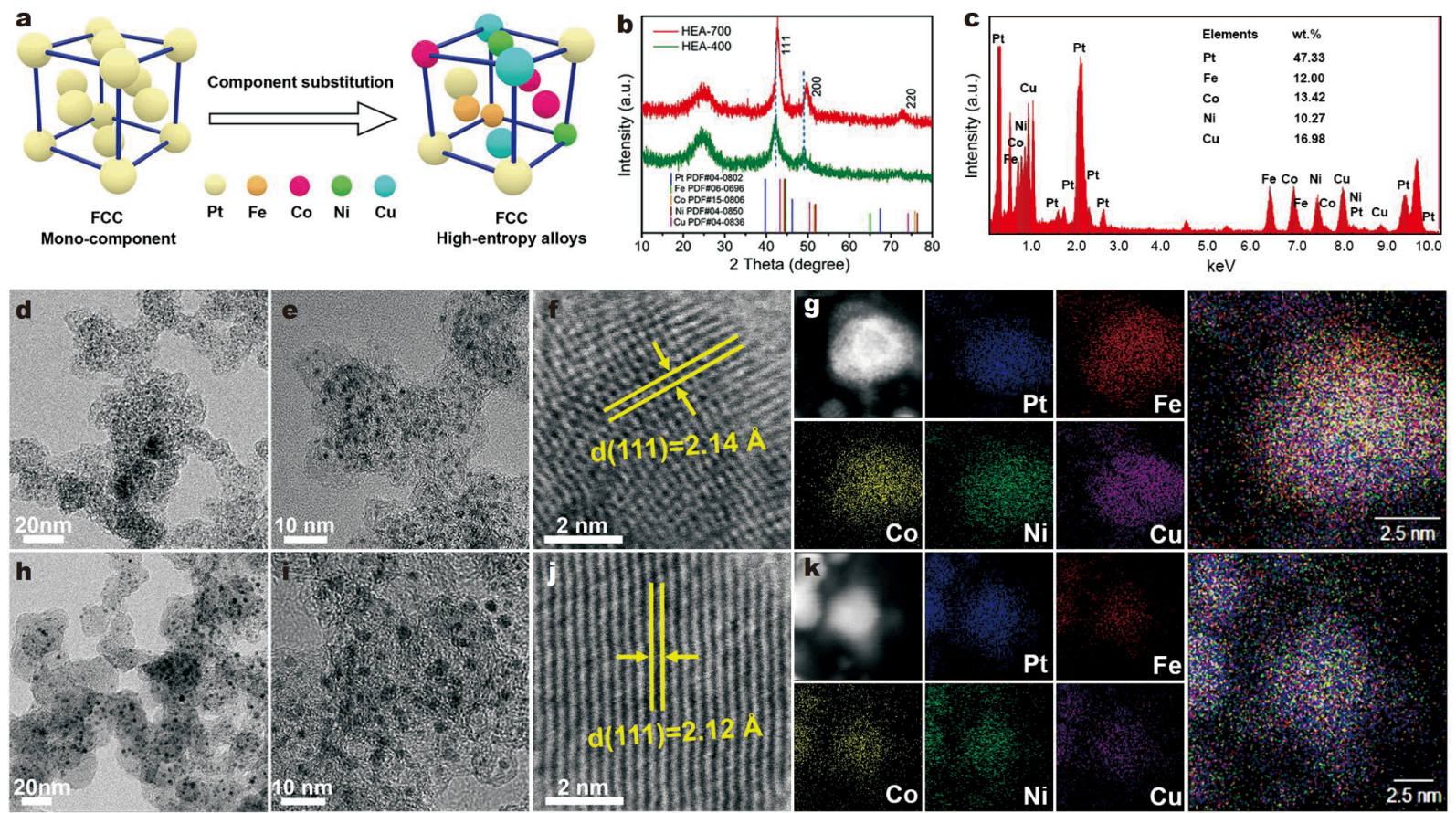

Figure 1 Structural, morphological, and elemental characterizations. (a) Schematic diagram of the transformation from pure metal element FCC structure to HEAs FCC structure. (b) The XRD patterns of HEA-400 and HEA-700. (c) STEM-EDS spectrum, (d, e) TEM images, (f) high-resolution STEM image, and (g) STEM-EDS elemental mapping of HEA-400. (h, i) TEM images, (j) high-resolution STEM image, and (k) STEM-EDS elemental mapping of HEA-700. 
The morphology and microstructure of the HEAs were observed by TEM, high-resolution TEM (HRTEM), and high-resolution aberration-corrected STEM. As shown in Fig. $1 d, e, h$ and $i$, the low magnification TEM images of HEA-400 and HEA-700 show a morphology of ultrasmall nanoparticles. Specifically, the average sizes of HEA nanoparticles for HEA-400 and HEA-700 are 1.41 and $2.37 \mathrm{~nm}$, respectively (Fig. S4). This is the smallest nanoparticle size for HEAs reported in the references $[9,11,30,31]$. This facilitates exposing more reactive sites for the electrocatalytic process due to the large specific surface area (Table S2). High-resolution STEM image of a single HEA-400 nanoparticle (Fig. If and Fig. S3b) shows lattice fringes with a spacing of $2.14 \AA$, which is close to but smaller than that of (111) plane of cubic Pt crystal (2.22 $\AA$, JCPDS No. 04-0802), indicating the incorporation of transition metal ( $\mathrm{Fe}, \mathrm{Ni}, \mathrm{Cu}$ and $\mathrm{Co}$ ) atoms into the Pt nanostructure. After the high temperature treatment, the high-resolution STEM image of a single HEA700 nanoparticle (Fig. $1 \mathrm{j}$ and Fig. S3c) shows lattice fringes with a spacing of $2.12 \AA$, which exhibits about $0.94 \%$ compressive strain compared with HEA- 400 , indicating that the high temperature treatment induced the generation of compression strain in HEAs. These TEM results are consistent with the XRD results. In addition, we found no apparent elemental segregation or phase separation for the HEA-400 and HEA-700 nanoparticles (Fig. 1j, k) using STEM elemental mapping. Highresolution aberration-corrected STEM and elemental mapping also demonstrate both uniform atomic scale mixing and the formation of an FCC crystalline structure.

To understand the surface valence states of the HEAs, XPS analysis was conducted. Fig. 2a shows the Pt 4 f XPS spectra of the HEA-400 and HEA-700. The binding energy of HEA-700 has a positive shift compared with that of HEA-400, indicating the downshift of the d-band centers [24,32]. The large change in Pt $4 \mathrm{f}$ binding energy will be conducive to reducing the $\mathrm{CO}$ adsorption energy and facilitating the $\mathrm{C}-\mathrm{H}$ bond fracture on Pt sites [33]. The Pt $4 \mathrm{f}$ XPS spectra of HEAs show two peaks that can be attributed to $\mathrm{Pt} 4 \mathrm{f}_{7 / 2}$ and $\mathrm{Pt} 4 \mathrm{f}_{5 / 2}$, and can be further divided into two modules, corresponding to the metallic $\mathrm{Pt}$ and Pt oxide species. Another feature between 68 and $70 \mathrm{eV}$ belongs to the characteristic peak of $\mathrm{Ni} 3 \mathrm{p}$ related to $\mathrm{Ni}^{2+}$ in HEAs [34]. This phenomenon is often observed in PtNi alloy systems, which may be because that $\mathrm{Ni}$ has a strong affinity for oxygen [35]. Fig. S5a shows the Fe 2p XPS spectra of HEAs catalysts. The metallic Fe peak is located at $709.7 \mathrm{eV}$, while the peaks at 711.8 and $713.8 \mathrm{eV}$ can be assigned to $\mathrm{Fe}^{2+}$ and $\mathrm{Fe}^{3+}$ in HEAs, respectively.
The Co $2 p$ XPS spectra of the HEAs are given in Fig. S5b, the binding energies of the Co $2 p_{3 / 2}$ and Co $2 p_{1 / 2}$ peaks at 779.6 and $794.6 \mathrm{eV}$ are characteristics of metallic Co, and the couple peaks at 781.7 and $796.7 \mathrm{eV}$ are the feature of $\mathrm{Co}^{2+}$. Similarly, the Ni 2p XPS spectra (Fig. S5c) also reveal that the HEAs contains metallic $\mathrm{Ni}$ and its oxides. In the $\mathrm{Cu} 2 \mathrm{p}$ XPS spectra (Fig. S5d), a higher $\mathrm{Cu} 2 \mathrm{p}_{3 / 2}$ peak located at $932.7 \mathrm{eV}$ and an associated $\mathrm{Cu} 2 \mathrm{p}_{1 / 2}$ peak at $952.5 \mathrm{eV}$ are assigned to the metallic $\mathrm{Cu}$ species. The peaks at 933.8 and $953.5 \mathrm{eV}$ are attributed to the oxidation of $\mathrm{Cu}$.

In order to quantitatively express the influence of compression strain on the electronic structure of HEAs in MOR, the surface valance band photoemission spectrum (VBS) was carried out (Fig. 2b, c). Obviously, compared with HEA-400, the HEA-700 has a lower d-band centers due to the compressive strain, which can regulate the adsorption/desorption capacities of activating reactant or intermediates and improve the electrocatalytic activity in MOR [36-38]. This result is consistent with the above XPS analysis of the Pt $4 \mathrm{f}$ XPS spectra. To identify the atomic-coordination nature and electronic structure of the lattice-strained HEAs, we performed X-ray absorption near-edge structure (XANES) spectra and the EXAFS measurements. The absorption features of HEA-400 and HEA-700 are different from pure Pt, suggesting alloying of $\mathrm{Pt}$ with transition metals adjusted the electronic structure (Fig. 2d, e). The white-line intensities in these spectra reflect the oxidation states of the Pt species in the different samples [39]. Notably, the higher white-line intensity in HEA-400 than that in HEA-700 (inset in Fig. 2d) suggests that the Pt in HEA-400 carried more positive charge [40]. In addition, compared with the $\mathrm{Pt}$ XPS spectra of HEA-400, it was also observed that Pt showed a higher proportion of metallic states on the surface of HEA-700 catalysts. Therefore, HEA-700 exhibits a significantly lower oxidation state of the Pt species compared with HEA-400, which may be attributed to better oxidation resistance and higher degree of alloying in HEAs under the influence of higher temperature treatment [41]. Fig. 2e and Fig. S6 show the radial distribution function (RDF) and the corresponding fitted data, respectively. The HEAs have a shorter bond length than that of pure $\mathrm{Pt}$, which indicates that transition metals were successfully alloyed with Pt to form a singlephase solid solution with some lattice contraction, consistent with the XRD and TEM analysis. The fitted $\mathrm{Pt}_{\mathrm{L}_{3}}$ edge EXAFS results of the HEA-400 and HEA-700 are described in Fig. S6 and Table S3, respectively. For the HEA catalysts, Pt-O bond was found, which may be 

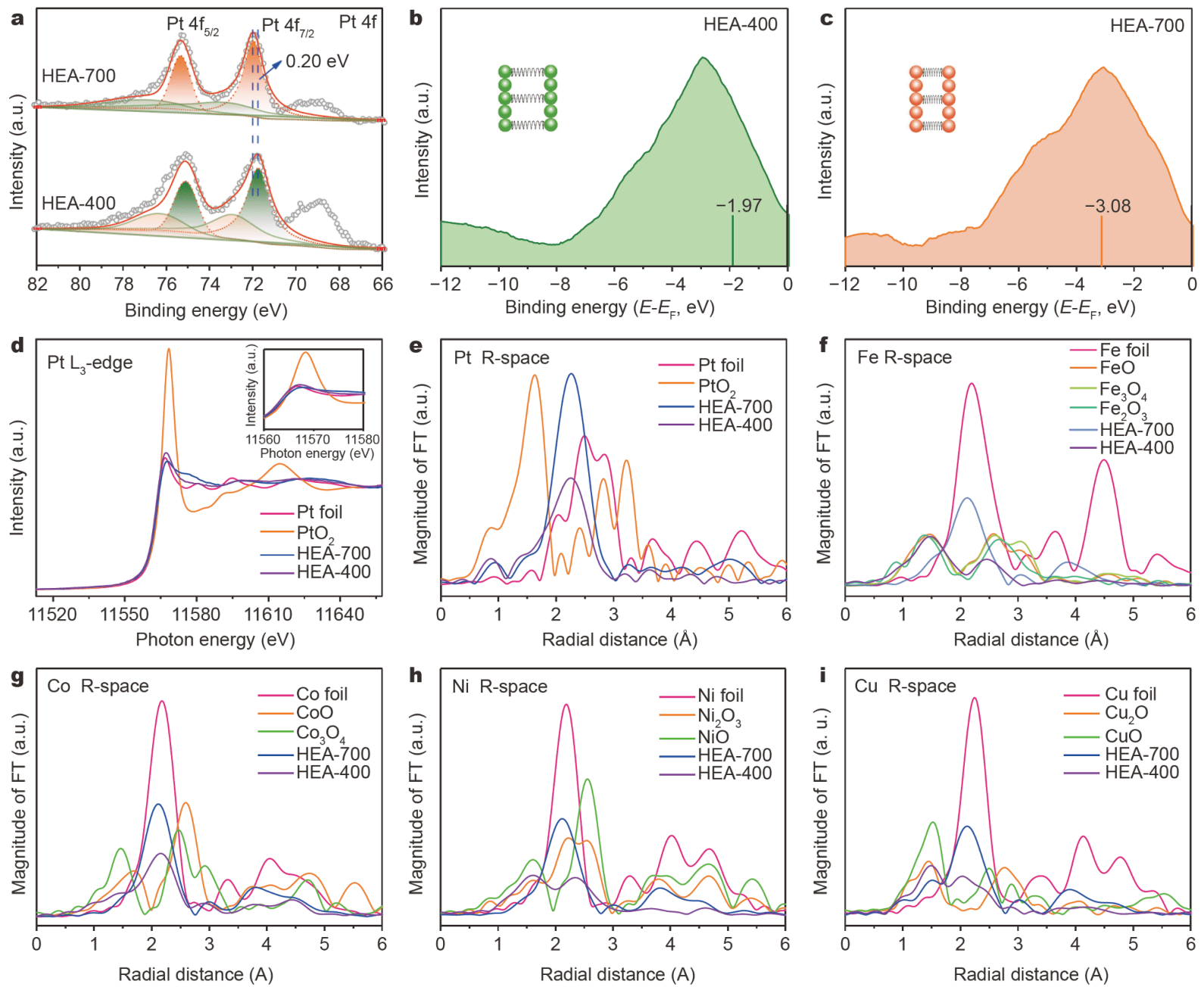

Figure 2 Local structure analyses. (a) Pt 4f XPS spectra of HEAs. Surface valence band photoemission spectra of (b) HEA-400 and (c) HEA-700. (d) Pt $\mathrm{L}_{3}$-edge XANES of HEAs as well as the reference samples. Inset shows the enlarged spectra at Pt $\mathrm{L}_{3}$-edge. The Fourier transform (FT) of the EXAFS spectra of HEAs as well as the reference samples: (e) Pt $\mathrm{L}_{3}$-edge, (f) Fe K-edge, (g) Co K-edge, (h) Ni K-edge, and (i) Cu K-edge.

because the catalysta are exposed to the air [42]. More importantly, judging from the fitted results (Table S3), the Pt-Pt bond distance $\left(R_{\mathrm{Pt}-\mathrm{Pt}}=2.57885 \AA\right)$ in HEA-700 is smaller than that of HEA-400 $\left(R_{\mathrm{Pt}-\mathrm{Pt}}=2.69068 \AA\right)$. According to previous research, the shorter $R_{\mathrm{Pt}-\mathrm{Pt}}$ can significantly improve electrocatalytic activity by tuning $\mathrm{d}$ band centers $[43,44]$. In addition, transition metal distributions in HEAs were also investigated by collecting their XANES and EXAFS. We find that $\mathrm{Fe}$ and $\mathrm{Ni}$ in HEA-400 are mainly in an oxidation state, while Co and $\mathrm{Cu}$ are relatively stable and only slightly oxidized (Fig. S7 and Fig. $2 \mathrm{f}-\mathrm{i}$ ); this may be because $\mathrm{Fe}$ and $\mathrm{Ni}$ have a strong affinity for oxygen and are often studied in simple binary Pt-based alloys [45]. Correspondingly, the EXAFS of the $\mathrm{Fe}$ and $\mathrm{Ni}$ closely resembles that of $\mathrm{FeO}$ and $\mathrm{NiO}$, respectively (Fig. $2 \mathrm{f}, \mathrm{h}$ ). Interestingly, they change dramatically in HEA-700 with the $\mathrm{Fe}-\mathrm{O}$ and $\mathrm{Ni}-\mathrm{O}$ bond peaks at $1.5 \AA$ disappears, and almost all transition metal elements in HEA-700 are alloying phase. The higher degree of alloying for HEA-700 compared with HEA-400 is very beneficial to the electrochemical cycling stability of the catalyst under operating conditions. The above analyses together prove that the $\mathrm{Fe}$ and $\mathrm{Ni}$ in the HEA-400 are in the multiple valence of $\mathrm{M}^{x+}(\mathrm{M}=\mathrm{Fe}$ and $\mathrm{Ni})$ and Pt-based alloying phase. According to previous reports, these surface $\mathrm{Fe}$ and Ni species will have no effect on the MOR activity because they will be completely dissolved in the early activation stage. Nevertheless, the $\mathrm{Fe}$ and $\mathrm{Ni}$ in the core is conducive to MOR not only because they increase the utilization of Pt but also optimize the electronic 
structure of the surface $\mathrm{Pt}$ sites by generating the compressive strain [23]. This is consistent with the fitted $\mathrm{Pt}$ $\mathrm{L}_{3}$-edge EXAFS results (Fig. S6 and Table S3).

The electrochemical behaviors of HEA-400, HEA-700 and $\mathrm{Pt} / \mathrm{C}$ catalysts were measured (Fig. 3a) by cyclic voltammetry $(\mathrm{CV})$. The reduction peak potential for Pt$\mathrm{OH}_{\mathrm{ad}}$ of HEA-700 is shifted forward compared with those of HEA-400 and Pt/C, which indicates HEA-700 has the weakest adsorption for oxygen-containing species [46]. Combining ECSA and ICP-OES analyses (Tables S4 and S5), as displayed in Fig. 3b, HEA-400 and HEA-700 de- liver superior MOR performance in $\mathrm{N}_{2}$-saturated $0.1 \mathrm{~mol} \mathrm{~L}^{-1} \mathrm{HClO}_{4}+1 \mathrm{~mol} \mathrm{~L}^{-1} \mathrm{CH}_{3} \mathrm{OH}$ solution with the specific activities (mass activity) of $2.35 \mathrm{~mA} \mathrm{~cm}^{-2}$ $\left(1.30 \mathrm{~A} \mathrm{mg}^{-1}\right)$ and $3.29 \mathrm{~mA} \mathrm{~cm}^{-2}\left(1.40 \mathrm{~A} \mathrm{mg}^{-1}\right)$, respectively, which are 1.57 (2.32) and 2.20 (2.50) times that of Pt/C (Fig. 3c) and higher than most of the state-of-the-art catalysts in recent reports (Table S6). In particular, HEA700 displays a higher catalytic activity compared with HEA-400. The high activity is partly caused by different surface compressive strain between them. As another important index, the ratio of peak current density of the
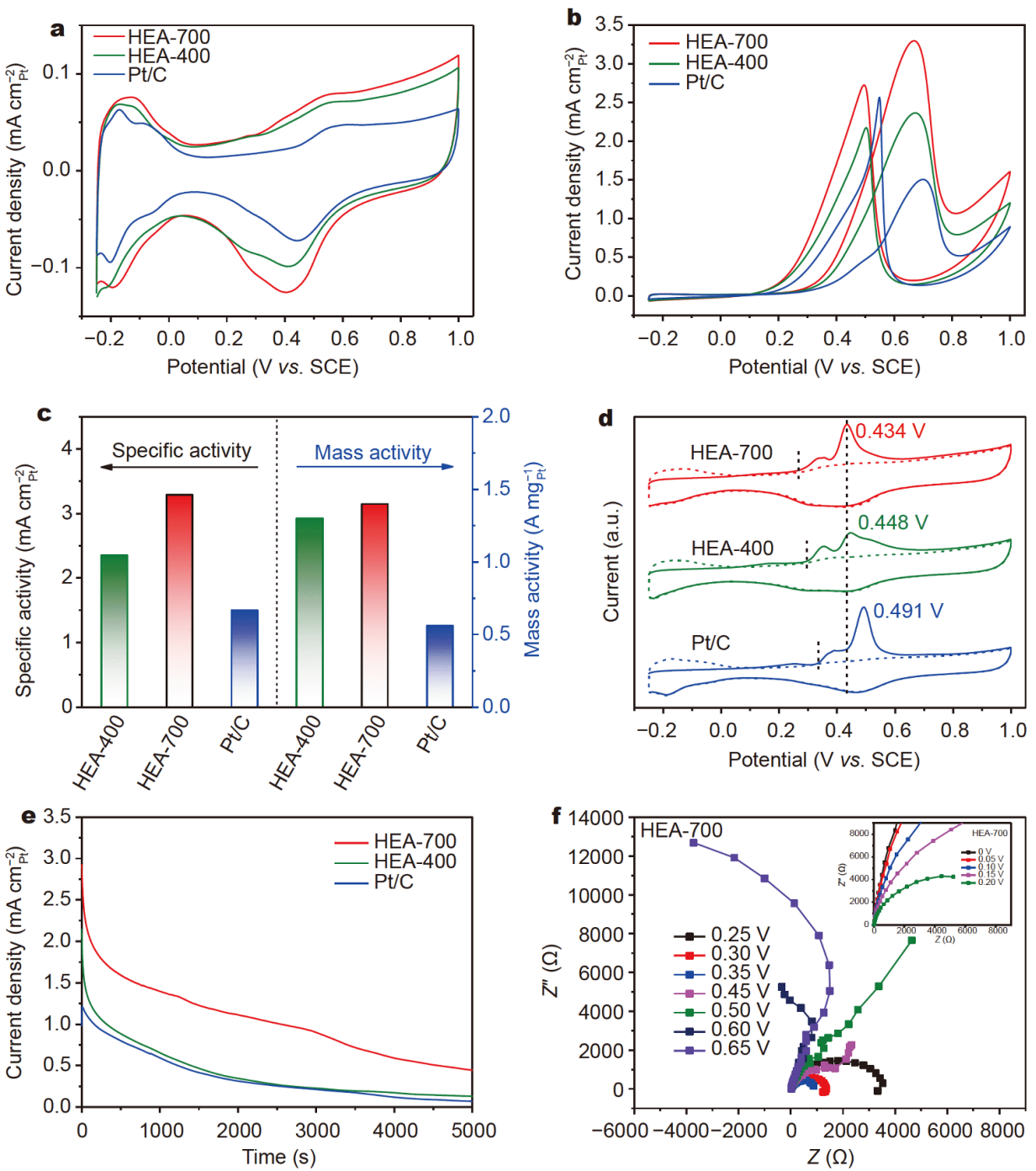

Figure 3 Electrocatalytic performance. (a) Cyclic voltammograms of Pt/C, HEA-400 and HEA-700 catalysts in $\mathrm{N}_{2}$-saturated $0.1 \mathrm{~mol} \mathrm{~L}^{-1} \mathrm{HClO}_{4}$ solution at a scan rate of $50 \mathrm{mV} \mathrm{s}^{-1}$. (b) Electrocatalytic activities of Pt/C, HEA-400 and HEA-700 catalysts in $\mathrm{N}_{2}$-saturated $1 \mathrm{~mol} \mathrm{~L}^{-1} \mathrm{CH}_{3} \mathrm{OH}+$ $0.1 \mathrm{~mol} \mathrm{~L}^{-1} \mathrm{HClO}_{4}$ solution at a scan rate of $50 \mathrm{mV} \mathrm{s}^{-1}$. (c) Specific activities and mass activities of Pt/C, HEA-400 and HEA-700 catalysts. (d) CO stripping voltammograms of HEA-700, HEA-400, and $\mathrm{Pt} / \mathrm{C}$ catalysts in $0.1 \mathrm{~mol} \mathrm{~L}^{-1} \mathrm{HClO}_{4}$ solution. (e) Chronoamperometric curves of the Pt/C, HEA-400 and HEA-700 catalysts in $1 \mathrm{~mol} \mathrm{~L}^{-1} \mathrm{CH}_{3} \mathrm{OH}+0.1 \mathrm{~mol} \mathrm{~L}^{-1} \mathrm{HClO}_{4}$ solution at $0.60 \mathrm{~V}$ for $5000 \mathrm{~s}$. (f) In operando Nyquist plots of EIS for MOR on HEA-700 catalyst at $0.25-0.65 \mathrm{~V}$. The inset shows Nyquist plots at $0-0.20 \mathrm{~V}$, where the applied voltage is referenced to the SCE. 
forward-to-backward scans $\left(I_{\mathrm{f}} / I_{\mathrm{b}}\right)$ can be applied to evaluate the tolerance of electrocatalysts to the poisoning of intermediate carbonaceous species in MOR [46,47]. The ratio (Fig. S8) indicates that HEA-700 $\left(I_{\mathrm{f}} / I_{\mathrm{b}}=1.21\right)$ has better poisoning tolerance than HEA-400 $\left(I_{\mathrm{f}} / I_{\mathrm{b}}=\right.$ 1.09) and $\mathrm{Pt} / \mathrm{C}\left(I_{\mathrm{f}} / I_{\mathrm{b}}=0.58\right)$. In addition, we further investigated the $\mathrm{CO}$ tolerance of $\mathrm{Pt} / \mathrm{C}, \mathrm{HEA}-400$ and HEA700 catalysts by $\mathrm{CO}$ stripping test in $0.1 \mathrm{~mol} \mathrm{~L}^{-1} \mathrm{HClO}_{4}$ (Fig. 3d and Fig. S9). The CO stripping curve of HEA-700 shows lower onset potential and peak potential $(0.434 \mathrm{~V})$ than those of HEA-400 $(0.448 \mathrm{~V})$ and $\mathrm{Pt} / \mathrm{C}(0.491 \mathrm{~V})$, indicating HEA-700 has a higher $\mathrm{CO}$ tolerance. The stability of the electrocatalysts were evaluated by CV cycling, as shown in Fig. S10. After 1000 cycles, the peak current density retention rate of HEA-700, HEA-400 and Pt/C are $72.5 \%, 69.4 \%$ and $53.5 \%$, respectively, demonstrating that HEA-700 has enhanced catalytic stability. Moreover, the durability of HEAs were then tested using chronoamperometry (Fig. 3e). It can be found that the current density decreased rapidly in the beginning, which was attributed to the adsorption of intermediate species on $\mathrm{Pt}$ surface in MOR [48]. As time progressed, the anodic current density of catalysts achieved a stable state, this may be due to that the intermediate adsorbing and oxidizing rate reached a balance. Obviously, the HEA-700 had a better ability to overcome catalytic poisoning than HEA-400 and Pt/C, and therefore showed consistently higher current density in duration measurements. In addition, we synthesized a series of HEAs with different Pt contents (including 5, 10 and $20 \mathrm{wt} \%$ ) to explore the effect of Pt content in high-entropy $\mathrm{PtFeCoNiCu}$ alloys on lattice strain, catalytic activity and catalytic stability. We found that the electrocatalytic activity for MOR gradually enhanced with the increase of $\mathrm{Pt}$ content in HEAs. Obviously, all the HEAs obtained by heat treatment at $700^{\circ} \mathrm{C}$ exhibit better activity, $\mathrm{CO}$ tolerance and stability compared with that obtained at $400^{\circ} \mathrm{C}$ (Fig. S11).

In order to further understand the mechanism of MOR, in operando EIS of HEA-700 electrodes towards MOR at various potentials are described in Fig. 3f, and Figs S12 and S13. The EIS indicates that the MOR on HEA-700 at different potentials show distinguishing impedance characteristics [49]. At low voltages, a large arc was observed, and this spectral feature indicated the presence of impedance. The reaction has undergone a slow kinetic process because the reaction intermediate $\mathrm{CO}$ blocked the Pt site and prevented the adsorption and dehydrogenation of methanol [50]. At the above stage, methanol dehydrogenation is the rate-determining step. As the potential increased, the charge-transfer resistance for
MOR gradually decreased. Interestingly, a classic pseudoinductive behavior was observed at 0.25 and $0.35 \mathrm{~V}$, where a small arc appeared in the fourth quadrant and its diameter decreased sharply as the potential increased $[51,52]$. At this stage, the $\mathrm{CO}_{\mathrm{ads}}$ intermediate can be removed by oxidation and Pt active sites were regenerated. Therefore, the MOR rate was accelerated. At 0.60 and $0.65 \mathrm{~V}$, a negative Faradaic impedance can be observed in the second quadrant. This interesting phenomenon further indicates the existence of an inductive component. The inductive behavior can be attributed to the formation of hydroxyl species on Pt sites. Generally, this hydroxyl species had the ability to oxidize and remove the adsorbed CO intermediates on the catalyst surface to promote MOR [53,54]. It can be seen that the impedance analysis result is consistent with those of CV measurements and $I_{\mathrm{f}} / I_{\mathrm{b}}$ value. In addition, when the potential is higher than $0.70 \mathrm{~V}$, the impedance plots return to the first quadrant and the diameter of the arc firstly decreases (from 0.70 to $0.90 \mathrm{~V}$ ) and then increases $(0.90$ to $1.0 \mathrm{~V}$ ). The increase of charge transfer resistance $\left(R_{\mathrm{ct}}\right)$ can be attributed to the oxidation of the Pt surface [54]. Moreover, the $R_{\mathrm{ct}}$ is an important parameter for electrocatalytic reactions. The fitted EIS results indicate that the $R_{\mathrm{ct}}$ of HEA-700 is smaller than that of the HEA-400 (Fig. S10d), confirming the better electrocatalytic activity with faster charge transfer for MOR.

In order to investigate the HEAs stability after MOR, we studied structural changes of HEAs. As shown in Fig. S14, after 1000 cycles, the XRD pattern demonstrated that the HEAs maintained the stability of their own FCC structure without any phase separation. However, the peak position was shifted to a lower angle compared with the original HEAs (Fig. 1b), which could be due to the dissolution of the transition metals at the edge of the catalyst. The dissolution of these transition metals often results in catalysts having some $\mathrm{Pt}$ rich surfaces. These $\mathrm{Pt}$ atoms are in a defect-rich and highly reactive state and are often considered to be electrocatalytically active sites $[24,55]$. Moreover, we detected the actual Pt, Fe, Co, Ni and $\mathrm{Cu}$ contents in HEA-400 and HEA-700 after stability test by ICP-OES analysis. From the perspective of HEA definition, experimental data showed that the five elements in HEA-400 did not satisfy the requirement of equal mole ratios (Table S7). However, the molar ratio of $\mathrm{Pt}$ to transition metal $\mathrm{M}(\mathrm{M}=\mathrm{Fe}, \mathrm{Co}, \mathrm{Ni}$ and $\mathrm{Cu})$ in HEA-700 was close to 3:1 (Table S8). To a certain extent, this shows that HEA-700 has better structural stability than HEA-400. This is mainly attributed to HEA-700 having a higher alloying degree than HEA-400 and thus a 
slower dissolution rate of transition metals was obtained during stability testing. Subsequently, in order to obtain more surface information of the catalyst and observe the change of surface morphology, we performed TEM measurements after 1000 cycles. The results indicate that the surface morphologies of HEAs are retained well (Fig. S15a, c). Interestingly, HRTEM images of single HEA-400 and HEA-700 nanoparticles (Fig. S15b, d) show lattice fringes with spacings of $2.22 \AA$, which fits nicely with that of (111) plane of cubic Pt crystal (2.22 ̊, JCPDS No. 04-0802). It shows that the HEAs have a Pt-rich surface after 1000 cycles, which is consistent with the above XRD analysis. Further, we tested XPS of HEAs due to its high sensitivity to the surface of the electrocatalyst after the stability test. It was clear that the Pt $4 \mathrm{f}$ XPS spectrum had a strong signal, whereas other transition metals had almost no signal due to their low content on the catalyst surface (Fig. S16). The XPS results are also highly consistent with the above XRD, TEM and ICPOES measurements. These results suggest that the HEA700 had a better structural stability than HEA-400 due to the effect of compressive strain and higher alloying degree.

To gain further atomistic insights into the catalytic mechanisms of developed HEAs, DFT calculations were performed. We kept the bond length of Pt-Pt consistent with the experimental values (HEA-400: $2.69 \AA$ A HEA700: $2.58 \AA$ ), by setting the lattice constants of HEA-400 and HEA-700 to 10.76 and $10.32 \AA$, respectively, as depicted in Fig. 4a. As the atomic radii of $\mathrm{Fe}, \mathrm{Co}, \mathrm{Ni}$, and $\mathrm{Cu}$ are smaller than that of $\mathrm{Pt}$, the resultant HEA induces a compressive strain on the surface Pt layer, resulting in the shortened bond distance of Pt-Pt (2.69 $\AA$ for HEA-400, $2.58 \AA$ for HEA-700) from the original bond distance of Pt-Pt (2.81 $\AA$ ) on Pt(111). Fig. $4 \mathrm{~b}$ displays the adsorption energies of $\mathrm{CO}$ on the (111) surface of Pt, HEA-400 and HEA-700, wherein it is indicated that the adsorption energies of CO on HEA are much weaker than that on Pt (111). Note that after high-temperature treatment, the achieved smaller bond length of Pt-Pt $(2.58 \AA)$ in HEA700 would lead to a weaker adsorption of $\mathrm{CO}$, indicating a high CO tolerance and promoting methanol oxidation. Moreover, as reported in our previous study, the adsorption sites of HEAs are very complex, including ligand effect (spatial arrangement of different elements) and coordination effect (different crystal facets and defects) due to the nature of high entropy [56]. In the current work, 16 surface Pt atoms are considered with different ligand environments, as shown in Fig. S17 and Table S9. We find that electrons transfer to the surface Pt atoms from transition metal atoms. Interestingly, the adsorption energy of $\mathrm{CO}$ is observed to be linearly dependent on the electron transfer, as demonstrated in Figs S18 and S19, which could provide a meaningful route for further design of HEA catalysts. To reveal the CO adsorption properties on HEA surface, the electronic structures were
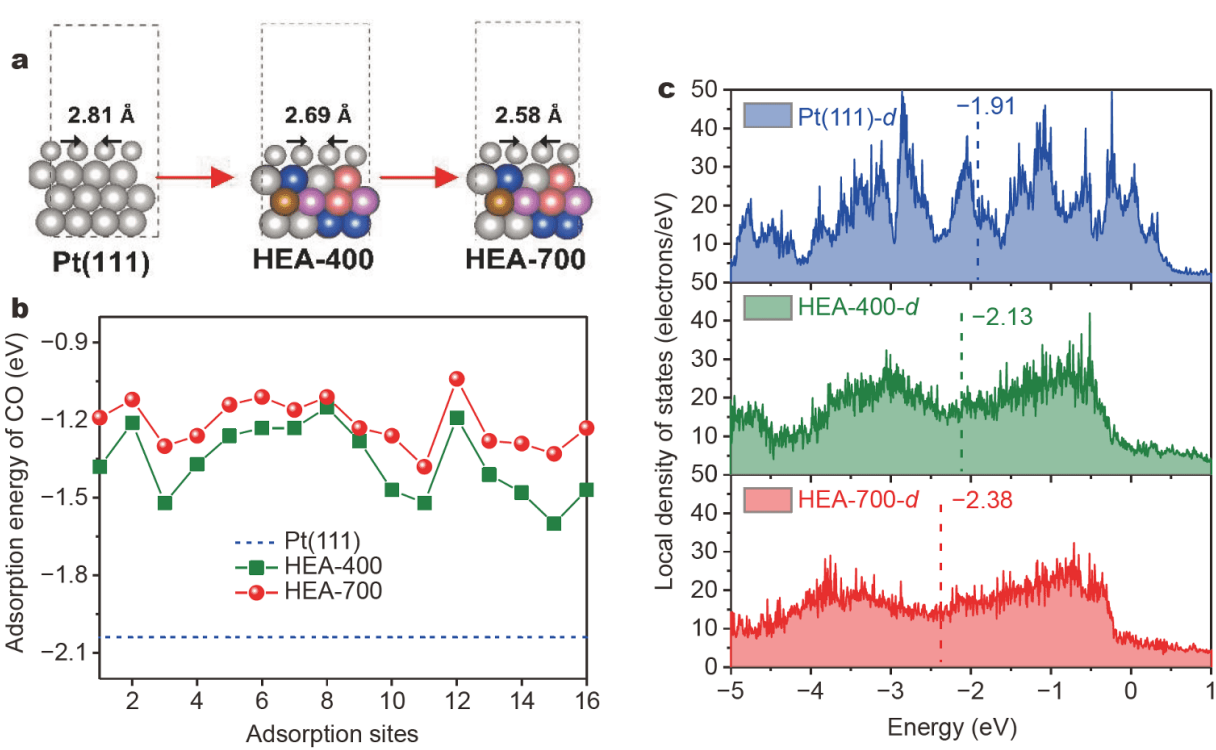

Figure 4 DFT calculations. (a) Geometrically optimized atomic structures of Pt(111), HEA-400 and HEA-700. Sliver, yellow, purple, pink, and blue balls represent $\mathrm{Pt}, \mathrm{Fe}, \mathrm{Co}, \mathrm{Ni}$, and $\mathrm{Cu}$ atoms. The small sliver balls indicate the surface Pt atoms. (b) Adsorption energies of $\mathrm{CO}$ on Pt(111), $\mathrm{HEA}-400$ and HEA-700. (c) d-Orbitals of surface Pt atoms in the systems of Pt(111), HEA-400 and HEA-700. The dotted line represents the d-band centers. 
analyzed by plotting the local density of states for the dorbitals (Fig. 4c). Importantly, this figure shows that the d-band centers of Pt(111), HEA-400, and HEA-700 are at $-1.91,-2.13$ and $-2.38 \mathrm{eV}$, respectively, suggesting that the compression strain in HEA makes the d-band center of surface Pt layer moving away from the Fermi energy, resulting in a weaker adsorption of CO on HEA-700. The DFT results also indicate that HEA-700 has a high CO tolerance, which agrees with our experimental results.

\section{CONCLUSIONS}

To summarize, we have successfully synthesized a class of ultra-fine $\mathrm{PtFeCoNiCu} \mathrm{HEAs} \mathrm{by} \mathrm{the} \mathrm{impregnation} \mathrm{re-}$ duction method, which exhibits remarkable specific activity and CO tolerance for MOR. EXAFS measurements reveal that the enhanced MOR activity could be due to a shorter Pt-Pt bond distance in HEA-700 resulting from compressive strain, which can significantly improve the electrocatalytic activity by tuning d-band centers. Moreover, DFT calculations indicate that compression strain shifts the d-band centers away from the Fermi energy, resulting in a weaker adsorption of CO on HEA-700 surface and consequently, a higher MOR catalytic activity. For all we know, this is the first time that the strain engineering has been used to regulate the electronic structure of HEAs for robust MOR performance. This work suggests that tailoring surface strains in HEAs is a promising strategy for developing advanced catalytic materials.

Received 31 December 2020; accepted 3 February 2021; published online 14 May 2021

1 Zeb Gul Sial MA, Ud Din MA, Wang X. Multimetallic nanosheets: Synthesis and applications in fuel cells. Chem Soc Rev, 2018, 47: 6175-6200

2 Zhang W, Yang Y, Huang B, et al. Ultrathin PtNiM ( $\mathrm{M}=\mathrm{Rh}$, Os, and Ir) nanowires as efficient fuel oxidation electrocatalytic materials. Adv Mater, 2019, 31: 1805833

3 Xia BY, Wu HB, Li N, et al. One-pot synthesis of Pt-Co alloy nanowire assemblies with tunable composition and enhanced electrocatalytic properties. Angew Chem Int Ed, 2015, 54: 37973801

4 Li J, Jilani SZ, Lin $\mathrm{H}$, et al. Ternary CoPtAu nanoparticles as a general catalyst for highly efficient electro-oxidation of liquid fuels. Angew Chem Int Ed, 2019, 58: 11527-11533

5 Rethinasabapathy M, Kang SM, Haldorai Y, et al. Quaternary PtRuFeCo nanoparticles supported $\mathrm{N}$-doped graphene as an efficient bifunctional electrocatalyst for low-temperature fuel cells. J Ind Eng Chem, 2019, 69: 285-294

6 Lei $\mathrm{Z}$, Liu X, Wu Y, et al. Enhanced strength and ductility in a high-entropy alloy via ordered oxygen complexes. Nature, 2018, 563: $546-550$

7 Ding Q, Zhang Y, Chen X, et al. Tuning element distribution, structure and properties by composition in high-entropy alloys. Nature, 2019, 574: 223-227

8 El-Atwani O, Li N, Li M, et al. Outstanding radiation resistance of tungsten-based high-entropy alloys. Sci Adv, 2019, 5: eaav2002

9 Yao Y, Huang Z, Xie P, et al. Carbothermal shock synthesis of high-entropy-alloy nanoparticles. Science, 2018, 359: 1489-1494

10 Yang T, Zhao YL, Tong Y, et al. Multicomponent intermetallic nanoparticles and superb mechanical behaviors of complex alloys. Science, 2018, 362: 933-937

11 Bondesgaard M, Broge NLN, Mamakhel A, et al. General solvothermal synthesis method for complete solubility range bimetallic and high-entropy alloy nanocatalysts. Adv Funct Mater, 2019, 29: 1905933

12 Cantor B, Chang ITH, Knight P, et al. Microstructural development in equiatomic multicomponent alloys. Mater Sci Eng-A, 2004, 375-377: 213-218

13 Yeh JW, Chen SK, Lin SJ, et al. Nanostructured high-entropy alloys with multiple principal elements: Novel alloy design concepts and outcomes. Adv Eng Mater, 2004, 6: 299-303

14 Zhang Y, Zuo TT, Tang Z, et al. Microstructures and properties of high-entropy alloys. Prog Mater Sci, 2014, 61: 1-93

15 Tsai KY, Tsai MH, Yeh JW. Sluggish diffusion in Co-Cr-Fe-MnNi high-entropy alloys. Acta Mater, 2013, 61: 4887-4897

16 Yeh JW, Chang SY, Hong YD, et al. Anomalous decrease in X-ray diffraction intensities of $\mathrm{Cu}-\mathrm{Ni}-\mathrm{Al}-\mathrm{Co}-\mathrm{Cr}-\mathrm{Fe}-\mathrm{Si}$ alloy systems with multi-principal elements. Mater Chem Phys, 2007, 103: 41-46

17 Zhang W, Liaw PK, Zhang Y. Science and technology in highentropy alloys. Sci China Mater, 2018, 61: 2-22

18 Lacey SD, Dong Q, Huang Z, et al. Stable multimetallic nanoparticles for oxygen electrocatalysis. Nano Lett, 2019, 19: 51495158

19 Qiu HJ, Fang G, Wen Y, et al. Nanoporous high-entropy alloys for highly stable and efficient catalysts. J Mater Chem A, 2019, 7: 6499-6506

20 Qiu HJ, Fang G, Gao J, et al. Noble metal-free nanoporous highentropy alloys as highly efficient electrocatalysts for oxygen evolution reaction. ACS Mater Lett, 2019, 1: 526-533

21 Luo M, Guo S. Strain-controlled electrocatalysis on multimetallic nanomaterials. Nat Rev Mater, 2017, 2: 17059

22 Wang $\mathrm{H}, \mathrm{Xu} \mathrm{S}$, Tsai C, et al. Direct and continuous strain control of catalysts with tunable battery electrode materials. Science, 2016, 354: 1031-1036

23 Strasser P, Koh S, Anniyev T, et al. Lattice-strain control of the activity in dealloyed core-shell fuel cell catalysts. Nat Chem, 2010, 2: $454-460$

24 Qin Y, Zhang W, Guo K, et al. Fine-tuning intrinsic strain in penta-twinned $\mathrm{Pt}-\mathrm{Cu}-\mathrm{Mn}$ nanoframes boosts oxygen reduction catalysis. Adv Funct Mater, 2020, 30: 1910107

$25 \mathrm{Bu} \mathrm{L}$, Zhang N, Guo S, et al. Biaxially strained $\mathrm{PtPb} / \mathrm{Pt}$ core/shell nanoplate boosts oxygen reduction catalysis. Science, 2016, 354: 1410-1414

26 Wang D, Xin HL, Hovden R, et al. Structurally ordered intermetallic platinum-cobalt core-shell nanoparticles with enhanced activity and stability as oxygen reduction electrocatalysts. Nat Mater, 2013, 12: 81-87

27 Chen L, Zhu J, Xuan C, et al. Effects of crystal phase and composition on structurally ordered $\mathrm{Pt}-\mathrm{Co}-\mathrm{Ni} / \mathrm{C}$ ternary intermetallic electrocatalysts for the formic acid oxidation reaction. J Mater Chem A, 2018, 6: 5848-5855

28 Wei PC, Liao CN, Wu HJ, et al. Thermodynamic routes to ultralow 
thermal conductivity and high thermoelectric performance. Adv Mater, 2020, 32: 1906457

29 Lee C, Kim G, Chou Y, et al. Temperature dependence of elastic and plastic deformation behavior of a refractory high-entropy alloy. Sci Adv, 2020, 6: eaaz4748

30 Sonkusare R, Swain A, Rahul MR, et al. Establishing processingmicrostructure-property paradigm in complex concentrated equiatomic CoCuFeMnNi alloy. Mater Sci Eng-A, 2019, 759: 415429

31 Broge NLN, Bondesgaard M, Søndergaard-Pedersen F, et al. Autocatalytic formation of high-entropy alloy nanoparticles. Angew Chem Int Ed, 2020, 59: 21920-21924

32 Li C, Yuan Q, Ni B, et al. Dendritic defect-rich palladium-coppercobalt nanoalloys as robust multifunctional non-platinum electrocatalysts for fuel cells. Nat Commun, 2018, 9: 3702

33 Wang L, Yamauchi Y. Metallic nanocages: Synthesis of bimetallic Pt-Pd hollow nanoparticles with dendritic shells by selective chemical etching. J Am Chem Soc, 2013, 135: 16762-16765

34 Dutta A, Ouyang J. Ternary NiAuPt nanoparticles on reduced graphene oxide as catalysts toward the electrochemical oxidation reaction of ethanol. ACS Catal, 2015, 5: 1371-1380

35 Becknell N, Kang Y, Chen C, et al. Atomic structure of $\mathrm{Pt}_{3} \mathrm{Ni}$ nanoframe electrocatalysts by in situ X-ray absorption spectroscopy. J Am Chem Soc, 2015, 137: 15817-15824

36 Jiang K, Wang P, Guo S, et al. Ordered PdCu-based nanoparticles as bifunctional oxygen-reduction and ethanol-oxidation electrocatalysts. Angew Chem Int Ed, 2016, 55: 9030-9035

37 Zhang J, Qu X, Han Y, et al. Engineering PtRu bimetallic nanoparticles with adjustable alloying degree for methanol electrooxidation: Enhanced catalytic performance. Appl Catal B-Environ, 2020, 263: 118345

38 Wang $\mathrm{H}$, Wang J, Pi Y, et al. Double perovskite $\mathrm{LaFe}_{x} \mathrm{Ni}_{1-x} \mathrm{O}_{3}$ nanorods enable efficient oxygen evolution electrocatalysis. Angew Chem Int Ed, 2019, 58: 2316-2320

39 Li YH, Xing J, Chen ZJ, et al. Unidirectional suppression of hydrogen oxidation on oxidized platinum clusters. Nat Commun, 2013, 4: 2500

40 Cheng X, Li Y, Zheng L, et al. Highly active, stable oxidized platinum clusters as electrocatalysts for the hydrogen evolution reaction. Energy Environ Sci, 2017, 10: 2450-2458

41 Senkov ON, Senkova SV, Dimiduk DM, et al. Oxidation behavior of a refractory $\mathrm{NbCrMo}_{0.5} \mathrm{Ta}_{0.5} \mathrm{TiZr}$ alloy. J Mater Sci, 2012, 47: 6522-6534

42 He C, Tao J. Pt loaded two-dimensional TaC-nanosheet/graphene hybrid as an efficient and durable electrocatalyst for direct methanol fuel cells. J Power Sources, 2016, 324: 317-324

43 Shao M, Chang Q, Dodelet JP, et al. Recent advances in electrocatalysts for oxygen reduction reaction. Chem Rev, 2016, 116: 3594-3657

44 Wang Q, Zhao Q, Su Y, et al. Hierarchical carbon and nitrogen adsorbed PtNiCo nanocomposites with multiple active sites for oxygen reduction and methanol oxidation reactions. J Mater Chem A, 2016, 4: 12296-12307

45 Jia Q, Zhao Z, Cao L, et al. Roles of Mo surface dopants in Enhancing the ORR performance of octahedral PtNi nanoparticles. Nano Lett, 2018, 18: 798-804

46 Zhang Y, Shi Y, Chen R, et al. Enriched nucleation sites for Pt deposition on ultrathin $\mathrm{WO}_{3}$ nanosheets with unique interactions for methanol oxidation. J Mater Chem A, 2018, 6: 23028-23033

47 Xue S, Deng W, Yang F, et al. Hexapod PtRuCu nanocrystalline alloy for highly efficient and stable methanol oxidation. ACS Catal, 2018, 8: 7578-7584

48 Wang $\mathrm{Q}$, Chen $\mathrm{S}$, Li P, et al. Surface Ru enriched structurally ordered intermetallic PtFe@PtRuFe core-shell nanostructure boosts methanol oxidation reaction catalysis. Appl Catal B-Environ, 2019, 252: 120-127

$49 \mathrm{Wu}$ G, Li L, Xu BQ. Effect of electrochemical polarization of PtRu/ C catalysts on methanol electrooxidation. Electrochim Acta, 2004, 50: $1-10$

50 Gorle DB, Velacheri Kumman V, Kulandainathan MA. Highly efficient, large surface area and spherically shaped Pt particles deposited electrolytically synthesized graphene for methanol oxidation with impedance spectroscopy. Int J Hydrogen Energy, 2017, 42: $16258-16268$

51 Hsing IM, Wang X, Leng YJ. Electrochemical impedance studies of methanol electro-oxidation on $\mathrm{Pt} / \mathrm{C}$ thin film electrode. J Electrochem Soc, 2002, 149: A615

52 Chen W, Kim J, Sun S, et al. Composition effects of FePt alloy nanoparticles on the electro-oxidation of formic acid. Langmuir, 2007, 23: 11303-11310

53 Zhang Y, Qiao M, Huang Y, et al. In situ exfoliation and Pt deposition of antimonene for formic acid oxidation via a predominant dehydrogenation pathway. Research, 2020, 2020: 1-11

54 Chen W, Kim J, Sun S, et al. Electro-oxidation of formic acid catalyzed by FePt nanoparticles. Phys Chem Chem Phys, 2006, 8: 2779-2786

55 Li J, Sharma S, Liu X, et al. Hard-magnet $\mathrm{L}_{10}-\mathrm{CoPt}$ nanoparticles advance fuel cell catalysis. Joule, 2019, 3: 124-135

56 Lu Z, Chen ZW, Singh CV. Neural network-assisted development of high-entropy alloy catalysts: Decoupling ligand and coordination effects. Matter, 2020, 3: 1318-1333

Acknowledgements This work was supported by the National Natural Science Foundation of China (51402100, 21573066, 21825201, 22002039, and 21522305), the Scientific Research Foundation of Hunan Provincial Education Department (19C0054), the Postgraduate Scientific Research Innovation Project of Hunan Province (CX20200441), the Australian Research Council (CE 140100012)| the Australian National Fabrication Facility | UOW Electron Microscopy Centre, and Compute Canada, Natural Sciences and Engineering Research Council of Canada (NSERC), University of Toronto.

Author contributions Wang S, Singh CV, Tao L, Zhang Y, Chen J and Dong CL conceived the idea and directed the research. Wang D, Chen Z, Huang YC and Li W designed the experiments. Wang D, Li W, Wang J, Gu K, Huang $\mathrm{X}$, Chen $\mathrm{J}$ and Wang $\mathrm{T}$ synthesized the materials and carried out the XRD, XPS, TEM and STEM physical characterizations. Huang $\mathrm{Y}$ and Dong CL did the XANES and EXAFS experiments. Wang $\mathrm{D}$, Zhang $\mathrm{Y}, \mathrm{Wu} \mathrm{Y}$ and Chen $\mathrm{C}$ completed the electrochemical tests. Chen $\mathrm{Z}, \mathrm{Lu} \mathrm{Z}$ and Singh CV provided the DFT calculation for this work. Wang D, Chen Z, Huang YC and Li W wrote the paper with comments from all authors.

Conflict of interest The authors declare that they have no conflict of interest.

Supplementary information online version of the paper.
Supporting data are available in the 


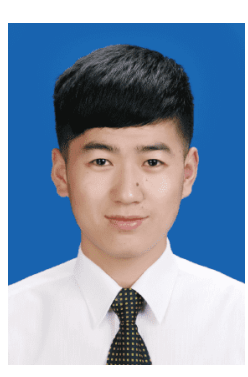

Dongdong Wang received his Bachelor degree in 2018 from Hunan University of Science and Technology, China. He is currently pursuing his $\mathrm{PhD}$ degree under the supervision of Prof. Shuangyin Wang at Hunan University. His research interest includes the synthesis, characterization of nanomaterials for electrocatalysis and electrochemical coupling.

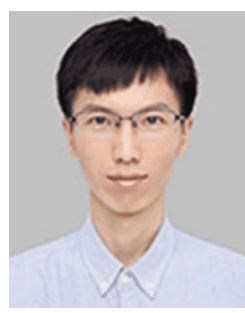

Zhiwen Chen works as a postdoctoral fellow in the Department of Materials Science and Engineering (MSE) at the University of Toronto, Canada. He received his $\mathrm{PhD}$ degree from Jilin University, China. His current research focuses on the catalyst design for hydrogen evolution reaction, $\mathrm{CO}_{2}$ reduction reaction, nitrogen reduction reaction, etc. through density functional theory calculations. Some of his studies are carried out in close collaboration with experiments.

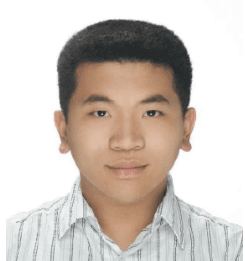

Yu-Cheng Huang received his BSc degree from Tamkang University in 2015, and obtained his MSc degree in the Department of Electrophysics from Chiao Tung University in 2017. He started studying for PhD in the Department of Electrophysics, Chiao Tung University in 2017. His research focuses on fundamental XAS analysis, including XANES, EXAFS and soft X-ray in-situ measurement techniques.

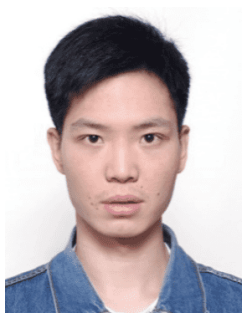

Wei Li received his BSc degree in 2013 from Huazhong Agricultural University and his PhD degree in 2018 from Chongqing University under the supervision of Prof. Zidong Wei. He currently works at Hunan University as a postdoctoral researcher under the co-supervision of Prof. Shuangyin Wang. His main research focuses on the development of defective nanomaterials in fuel cell application.

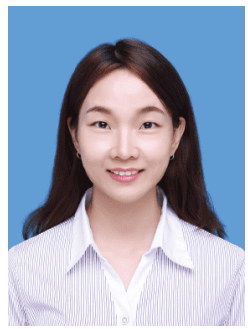

Yiqiong Zhang received her Master degree in 2015 from South China Normal University and her $\mathrm{PhD}$ degree in 2019 from Hunan University under the supervision of Prof. Shuangyin Wang. She is currently working at the College of Materials Science and Engineering, Changsha University of Science \&Technology. Her current research interests include the synthesis and characterization of nanomaterials with various defects for electrochemical energy conversion and storage technologies.

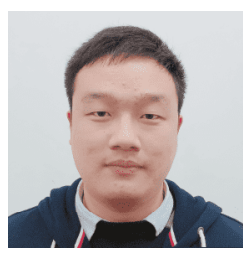

Li Tao received his Master degree in 2016 and his $\mathrm{PhD}$ degree in 2019 from Hunan University under the supervision of Prof. Shuangyin Wang. $\mathrm{He}$ is currently an assistant professor of the key Laboratory for Graphene Materials and Devices and College of Chemistry and Chemical Engineering, Hunan University. His research interests are in plasma technology, defect chemistry and fuel cell.

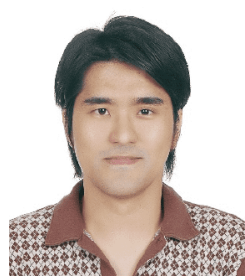

Chung-Li Dong received his $\mathrm{PhD}$ degree in physics from Tamkang University in 2004 . $\mathrm{He}$ then worked as a postdoctoral fellow at the Advanced Light Source Facility (Lawrence Berkeley National Laboratory) with Prof. Jinghua Guo. Now he joined the Department of Physics at Tamkang University as Associate Professor. His current research interests include the development of electrochromic, gaschromic and thermochromic related soft/hard X-ray in-situ reactors, lithium battery systems, supercapacitor systems, and electrocatalytic hydrogen production catalysts.

Jun Chen received his $\mathrm{PhD}$ degree at the School of Chemistry, University of Wollongong, Australia, in 2003. Professor Chen is a Chief Investigator of The ARC Centre of Excellence for Electromaterials Science (ACES). His research interests include sustainable energy devices/systems, electro-/bio- interfaces, nano/micro-materials, $2 \mathrm{D} / 3 \mathrm{D}$ printing, and design and fabrication of smart electronic devices.

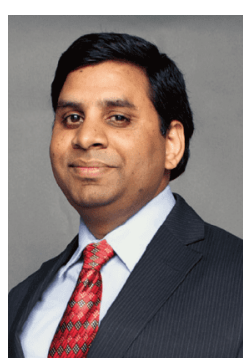

Chandra Veer Singh is the Erwin Edward Hart Endowed Associate Professor and Associate Chair of Research in the Department of Materials Science and Engineering at the University of Toronto, Canada. Dr Singh received his $\mathrm{PhD}$ degree in aerospace engineering from Texas A\&M University. Subsequently, he worked as a postdoctoral fellow at Cornell University. His research is currently focused on the atomistic modeling and machine learning enabled development of new materials for catalysts and metalion batteries.

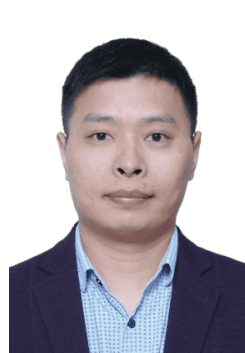

Shuangyin Wang received his BSc degree in 2006 from Zhejiang University and his $\mathrm{PhD}$ degree in 2010 from Nanyang Technological University, Singapore. He is currently a professor of the Key Laboratory for Graphene Materials and Devices and College of Chemistry and Chemical Engineering, Hunan University. His research interests are in plasma technology, defects in various crystals and their application for electrochemical energy storage and conversion. 
调控超细高熵合金晶格应变用于高活性和高稳定 性甲醇氧化

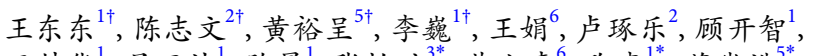

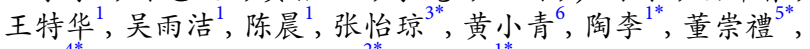
陈俊 ${ }^{4 *}$, Chandra Veer Singh ${ }^{2 *}$, 王双印 ${ }^{1 *}$

摘要 高熵合金(HEAs)因其非常规的组成和独特的物理化学性质 而得到广泛研究. 本文, 我们首次提出了一种表面应变策略来调控 HEAs的电子结构用于高效的甲醇电氧化反应(MOR). 高分辨像差 校正扫描透射电子显微镜(STEM)和元素分布分析表明, 在PtFeCo$\mathrm{NiCu}$ HEAs中各原子分散均匀, 并形成FCC 晶体结构. $700^{\circ} \mathrm{C}$ 热处理 所得HEA-700的压缩应变比 $400^{\circ} \mathrm{C}$ 热处理所得HEA-400的压缩应变 高 $0.94 \%$. 正如预期, HEA-700的比活性和质量活性远超HEA-400和 目前大多数最先进的催化剂. MOR活性的增强归因于压缩应变导 致HEA-700中Pt-Pt键距缩短. 同时, 核中的非贵金属原子通过转移 电子到表面Pt层产生压缩应变和 $\mathrm{d}$ 带中心的下移. 这项工作为高性 能HEAs电催化剂的设计提供了一个新的视角. 